\title{
The Future Computed. La inteligencia artificial y su papel en la sociedad y Pulsa actualizar. La aventura de redescubrir el alma de Microsoft y concebir un futuro mejor para todos
}

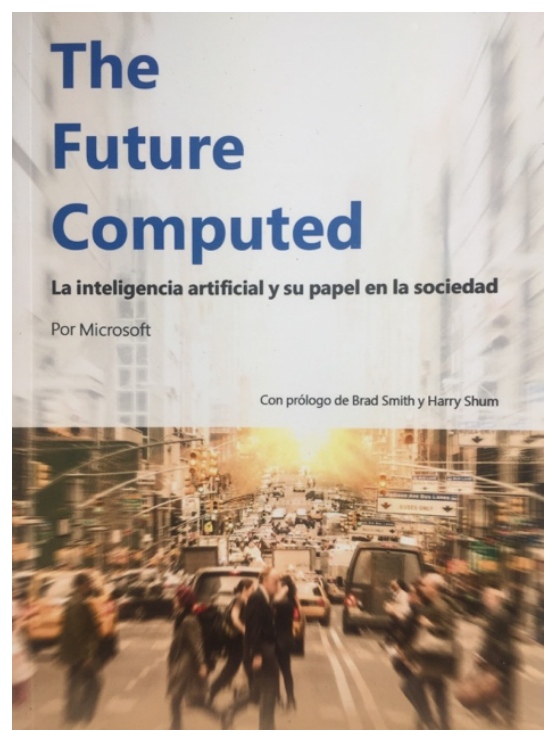

\author{
The Future Computed. La inteligencia \\ artificial y su papel en la sociedad \\ Microsoft \\ Washington: Microsoft Corporation, 2018 \\ 152 páginas
}

Reseña realizada por Gladys Arlette

Corona-León

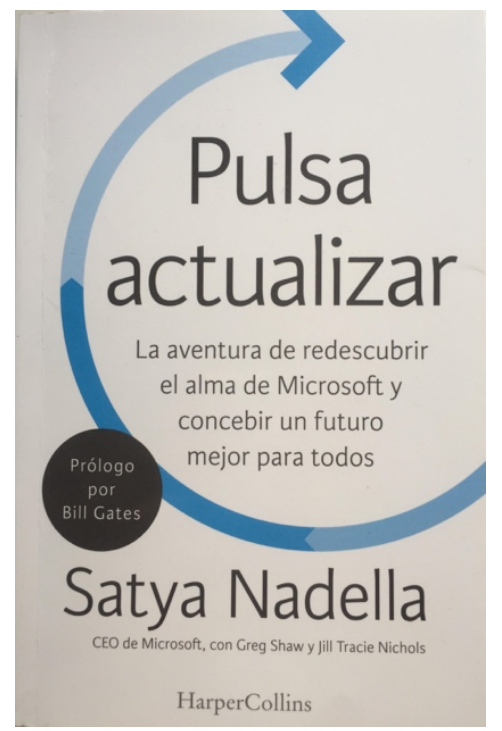

Pulsa actualizar. La aventura de redescubrir el alma de Microsoft $y$ concebir un futuro mejor para todos

Satya Nadella

Madrid: HarperCollins Ibérica, S.A., 2017

238 páginas

Reseña realizada por Gladys Arlette

Corona-León

\section{Forma de citar:}

Corona-León, G. A. (2019). The Future Computed. La inteligencia artificial y su papel en la sociedad y Pulsa actualizar. La aventura de redescubrir el alma de Microsoft y concebir un futuro mejor para todos. Ámbitos. Revista Internacional de Comunicación 46, pp. 268-270. doi: 10.12795/Ambitos.2019.i46.16 
DOI: http://dx.doi.org/10.12795/Ambitos.2019.i46.16

Microsoft traslada en sus páginas la siguiente premisa: "En 2038, los dispositivos digitales nos ayudarán a aprovechar mejor uno de nuestros bienes más preciados: el tiempo". Partiendo de el día a día de las personas, imaginemos un dispositivo inteligente que supervise tus constantes vitales en forma de asistente digital personal que automáticamente haga por ti tus tareas rutinarias para que dediques tu tiempo y energía a otros asuntos más importantes. Todo este proceso será gracias a la Inteligencia Artificial (IA), la cual, según los autores, ayuda a que los seres humanos aprovechen la gran cantidad de datos y optimicen sus recursos. Este escenario futurista y sus características que se plasman en cada párrafo, está cada vez más presente en nuestro entorno. Se conocen los beneficios de la tecnología digital pero también surgen preguntas sobre cómo afectara a la sociedad. Por ello en varios capítulos se menciona el uso de nuevas leyes y políticas públicas, incluso se habla de la creación de otras ramas del Derecho como por ejemplo la que vela por la protección de datos.

Adentrándonos en el tema, la evolución tecnológica hace pensar en las implicaciones éticas y sociales que lleva consigo. En un primer momento se han definido seis principios éticos para el uso y desarrollo de la Inteligencia Artificial: equidad, fiabilidad y seguridad, privacidad y protección, inclusividad, transparencia y responsabilidad.

Ante este horizonte tecnológico aparecen otras cuestiones que comparten los autores, ¿cómo afectará la Inteligencia Artificial al sector laboral? Se crearán algunos empleos y otros desaparecerán. De acuerdo con los historiadores económicos, en cada revolución industrial se incrementan las plazas de empleo, este supuesto es el que se espera, sin embargo no se puede predecir con certeza. Ante la presencia de nuevos campos de trabajo, la formación profesional también necesitara renovarse y las leyes laborales tendrán que abordar estas nuevas realidades.

El ámbito académico cambiará y los planes de estudio tendrán un rediseño. Las competencias que se necesitarán en un mundo impulsado por la Inteligencia Artificial serán los conocimientos informáticos y el análisis de datos; la ciencia, la tecnología, la ingeniería y las matemáticas. Las ciencias sociales y las humanidades retomarán importancia; estudios sobre el lenguaje, arte, historia, economía, ética, filosofía y desarrollo humano ofrecerán habilidades críticas y filosóficas que ayudarán al desarrollo y gestión de soluciones de Inteligencia Artificial.

Por lo tanto, se entiende que, la tecnología sin humanidades no tendrá futuro. Incluso esta dualidad la podemos ver reflejada en el perfil del actual CEO de Microsoft, Satya 
Nadella, que pone su sello humanista y tecnócrata en la empresa que dirige pues cree firmemente en la interacción de la empatía y la tecnología para transformar vidas, empresas y sociedades. Considera que el alma de Microsoft se encuentra en empoderar a las personas, no solo individualmente, sino también a las instituciones. Comparte que su cosmovisión de la tecnología conceptualiza la importancia que tiene la movilidad de la experiencia humana a través de todos los dispositivos.

Presenciando este panorama, ¿quién creará la tecnología relacionada con la Inteligencia Artificial? La compañía tecnológica fundada por Bill Gates en la década de 1970, escribe que se encuentran trabajando para democratizar la Inteligencia Artificial, es una responsabilidad compartida.

Los aspectos que se tratan en ambos libros nos hacen ver que el futuro es una ventana de incertidumbre. Sin embargo, Bill Gates, como visionario tecnológico, nos propone en sus líneas a ser optimistas y entender que el mundo está mejorando, la tecnología permitirá que nuestra vida sea más productiva y creativa. Las dos obras son imprescindibles para entender la historia y lo que está pasando en el mundo tecnológico y visualizar los escenarios que nos esperan desde la visión de una compañía referente en el sector tecnológico. 